information. The level of self-efficacy in occupational health surveillance and research increased significantly after the trainings. The highest increase was observed for research skills. Female students scored significantly higher on self-efficacy than men while no effect of age was demonstrated.

Conclusion Feedback on the implemented training programme was generally very favourable and participants were able to acquire competencies in the subject matter. Further details on the project and the different learning materials can be obtained free of charge and under Creative Commons licenses, at the project website http://www.esprit-ohs.eu/en/.

\section{INNOVATIONS IN EDUCATION AND TRAINING IN OSH}

${ }^{1}$ Frank JH van Dijk*, ${ }^{2}$ Marija Bubas. ${ }^{1}$ Foundation Learning and Developing Occupational Health (LDOH), Leiden, The Netherlands; ${ }^{2}$ Croatian Institute for Health Protections and safety at Work, Zagreb, Croatia

\subsection{6/oemed-2018-ICOHabstracts.265}

Aim of the session is to accelerate development, share and adopt innovative programs, processes and strategies in education in OSH Theodor Valerian Haratau ${ }^{1}$, Lena Kurtz ${ }^{2}$, Amanda Wolgast $^{3}$, Miwako Nagasu ${ }^{4}$, Anna Rask-Andersen ${ }^{5}$, Hans Thore Smedbold ${ }^{6}$

${ }^{1}$ Romtens Foundation, Bucharest, Romania

${ }^{2}$ Center for International Health LMU @ Institute and Clinic for Occupational, Social and Environmental Medicine, University Hospital, LMU Munich, Germany

${ }^{3}$ Prevent - Management and Labour Improving Work Environment, Stockholm, Sweden

${ }^{4}$ London School of Hygiene and Tropical Medicine, London, UK

${ }^{5}$ Department of Medical Sciences, Occupational and Environmental Medicine, Uppsala University, Uppsala, Sweden

${ }^{6}$ Board of Directors, Occupational Hygiene Training Association

\section{$1721 a$ TRAINING OCCUPATIONAL MEDICINE PHYSICIANS AND OSH EXPERTS WHO ARE PROVIDING THEIR SERVICES IN AGRICULTURE - AGROSH+}

${ }^{1}$ Theodor Valerian Haratau* ${ }^{2}$ Elena-Ana Păuncu, ${ }^{3}$ Pania Karnaki, ${ }^{4}$ Liupcho Kochouski, ${ }^{5}$ Richard Wynne. ${ }^{1}$ Romtens Foundation, Bucharest, Romania; ${ }^{2}$ University of Medicine and Pharmacy 'Victor Babes' (UMFVBT), Timisoara, Romania; ${ }^{3}$ Institute of Preventive Medicine Environmental and Occupational Health (PROLEPSIS), Marousi, Greece; ${ }^{4}$ Foundation 'Centre for Safety and Health at Work' (FCBZR), Sofia, Bulgaria; ${ }^{5}$ Work Research Centre (WRC), Dublin, Ireland

\subsection{6/oemed-2018-ICOHabstracts.266}

Introduction Agriculture as a sector has a tremendous impact on the European economy, it account for almost $40 \%$ of the EU budget, it is making use of almost $50 \%$ of the EU land, and its share of GDP has been increasing almost continuously for the past 5 years.

Nevertheless as the Eurofound (2016), Sixth European Working Conditions Survey has revealed, agriculture it is the least covered sector in terms of OSH. Moreover a research produced by the authors revealed the fact that in most of the EU-28 countries there are no specific training courses, crafted for agriculture, for occupational medicine physicians and for $\mathrm{OSH}$ experts.
Methods The AGROSH + project, is implemented by a consortium of 5 partners from 4 countries, countries to which agriculture is highly relevant -Bulgaria, Greece, Ireland and Romania, and produced two highly specific training courses dedicated to occupational medicine physicians and to $\mathrm{OSH}$ experts.

Results The training courses produced are blended, modular, of 40 hours each, and enclose modules such as musculoskeletal diseases, extreme temperatures, mental health in agriculture, health hazards in agriculture, toxicology, occupational cancer, etc. The courses are accredited, tested and benefit of a highly specific evaluation package based on the comprehensive Kirkpatrick four stages evaluation approach (it analyses the evolution of trainees' knowledge, skills, attitude and behaviour).

Conclusion The agriculture sector it is changing at a pace unseen before in terms of new chemical substances being used, of new technologies incorporated within classical tools, of climate changes and new environments where it is unfolded. Therefore the training of those experts who are providing their services (occupational medicine and OSH services) to agriculture needs to be performed using a specific and updated curriculum, using highly interactive platforms, using practical activities based on Case Studies, and especially by incorporating multidisciplinary expertise.

\section{$1721 \mathrm{~b}$ TRAINING IN OCCUPATIONAL SAFETY AND HEALTH: AN EFFECTIVE APPROACH TO FACE OSH CHALLENGES IN LATIN AMERICA}

L Kurtz*, K Radon, L Merz. Centre for International Health LMU @ Institute and Clinic for Occupational, Social and Environmental Medicine, University Hospital, LMU Munich, Germany

\subsection{6/oemed-2018-ICOHabstracts.267}

Introduction In the course of fast economic growth in Latin America, a wide range of production and services have been developed whereas the importance of occupational safety and health $(\mathrm{OSH})$ in these sectors still remain at a low level. To improve this situation well-trained professionals are necessary. Finding a lack of local training we established an education program for $\mathrm{OSH}$ professionals from Latin America who might act as regional leaders in $\mathrm{OSH}$ training and research (train the trainer model).

Methods Based on a needs assessment, we developed a twoyear blended learning Master consisting of onsite courses, project work and interactive online modules. Students receive theoretical and practical training in the assessment of working conditions, research skills and intervention strategies applying modern teaching methods and an international framework.

Results Since 2012, 91 OSH experts from 13 Latin American countries started the Master, 43 of them already graduated. After completing the program, over $80 \%$ of the graduates rate their knowledge in the OSH-fields taught in the Master as (very) high - compared to only one third before starting the program. Almost all graduates transfer this knowledge to their professional practice - even two years after completing the master. Today the graduates act as multipliers of OSH in their home countries by teaching at local universities, holding responsible positions and forming an international network. Over $70 \%$ of the former participants are still in contact at least once per month, realising further research projects, training courses, interventions and scientific publications. 